\title{
WORKSHOP DE NARRATIVAS MIX-MEDIA: PRODUÇÃO EM CONTEXTO DE EQUIPE MULTIDISCIPLINAR
}

\section{MIX-MEDIA NARRATIVES WORKSHOP: MULTIDISCIPLINARY TEAMS' PRODUCTION}

\author{
Sónia Liliana da Silva Vieira', Luís Manuel Frias²
}

RESUMO: O desenvolvimento das equipes de criação e produção de conteúdos, ào nível do design e publicação digital, seus processos e saberes transdisciplinares, estão a produzir transformações profundas nas estruturas de produção dos media e em seu próprio modelo de sustentabilidade profissional. O workshop de Narrativas Mix-media levado a cabo na Universidade da Beira Interior (Portugal) pretendeu desta forma simular a realidade das estruturas de produção e do recente paradigma das redações digitais integradas, bem como avaliar os desafios multi e transdiscisplinares dos vários saberes presentes na fabricação de conteúdos de mídias digitais. Alunos de design, jornalismo e cinema foram colocados perante situações reais de desenvolvimento editorial, e enquadrados com feedback profissional promovido em parceria com a redação do jornal Expresso.pt. Um membro da estrutura editorial do periódico supervisionou as sessões com a presença e apoio dos professores dos vários cursos envolvidos. Os dados recolhidos de notas de observação, fotos e vídeo, durante as sessões de trabalho laboratorial, foram cruzados com os resultados do inquérito, as análises e comentários feitos pelos professores envolvidos e as observações do profissional externo representante da equipe editorial do Expresso.pt. Pretendeu-se, assim, analisar de que forma futuros profissionais integrarão o desafio da colaboração em equipe multidisciplinar e produzirão conteúdos de caraterísticas mix-media com objetivos reais de publicação.

PALAVRAS-CHAVE: Design; Jornalismo; Cinema; Narrativa Mix-media; Multidisciplinar; Prototipagem.

ABSTRACT: The development of creation and content production teams, regarding design and digital publishing areas, their processes and transdisciplinary knowledge, are making deep changes in media production structures, and in its own professional sustainability model. The Mix-media Narratives Workshop that took place at Universidade da Beira Interior (Portugal) intended to simulate the reality of production structures and the recent integrated digital writing paradigm, as well as to evaluate the several multi and transdisciplinary challenges that may be present in the creation of digital media contents. Design, journalism and film production students were not only confronted with real editorial development situations, but also with professional feedback, which was possible due to a partnership with the newspaper Expresso.pt. A fellow editor from this newspaper kept track of the sessions, with the help and presence of professors from many of the courses involved. Data gathered from observation notes, pictures and video during laboratorial work meetings, was compiled and crossed with research results, analyses and comments made by the participant professors and Expresso. pt editor's observations. Our goal was to analyze in which way future workers will deal with the challenging task of collaborating with multidisciplinary teams and produce mix-media content with real publishing purpose.

KEYWORDS: Design; Journalism; Mix-media Narrative; Multidisciplinary; Prototypes. 


\section{CONTEXTO - LITERATURA}

Para a análise da ação formativa que trataremos nos próximos pontos, parece-nos fundamental começar por definir dois conceitos estruturantes para essa mesma análise, o de multidisciplinaridade e o de redação digital integrada. Como consideração inicial é importante notar que a teoria da convergência dos media e respetivas consequências na sua uniformização em torno dos meios digitais, bem como a alteração do relacionamento entre tecnologias, indústria e audiências (JENKINS, 2004), vão desencadear um processo de questionamento e desafio socioprofissional na área dos fazedores de conteúdos de media (HUANG et al., 2006), afetando jornalistas e designers, que aqui pretendemos destacar. A tendência atual para um caráter híbrido dos perfis profissionais, que os requisitos de produção da indústria dos media digitais promovem, cruza-se com um vetor contrário de atomização de funções e diversificação de papéis no terreno da produção de conteúdos, em concreto no campo do jornalismo digital. A premente necessidade de gestão deste processo dentro da indústria (GARCÍA-AVILÉS, 2011) levou à integração, num mesmo espaço, de culturas e competências técnico-profissionais separadas por décadas de prática segmentada. Processos produtivos até aí díspares como o jornalístico, o gráfico e/ou videográfico ou o informático necessitaram comungar de um mesmo plano de trabalho e suprimir os anteriores espaços que os distanciavam. Esta realidade vem definir o conceito de redação digital integrada, tal como é caracterizado por García-Avilés (2008), e um consequente processo de gestão de multicompetências num ambiente multidisciplinar.

Em seguida, identificamos três questões que situam este estudo no contexto da investigação na área e operacionalizam os conceitos anteriores, apresentando igualmente o conceito de mix-media digital como formato narrativo caraterístico dos conteúdos produzidos por uma redação digital integrada.

\section{OUTRAS EXPERIÊNCIAS DE ENSINO EM EQUIPE MULTIDISCIPLINAR: CASOS COM ESTUDANTES DE DESIGN E/OU JORNALISMO}

À semelhança das conclusões de Szenazy (2004) citadas por Fleischmann (2015), os problemas-base no desenvolvimento de práticas multidisciplinares, constrangimentos de tempo, competências dos professores e infraestrutura universitária são idênticos aos do sistema de ensino superior em design em Portugal. Em concreto no contexto interdepartamental da Faculdade de Artes e Letras da Universidade da Beira Interior (Covilhã, Portugal), onde este estudo foi conduzido, os cursos de Jornalismo, Design e Cinema têm pontos de contato muito tênues ao nível das unidades curriculares estruturais - as que detêm uma ligação direta com a prática profissional como é o caso de Produção Jornalística, Produção e Realização Multimedia ou Gêneros Cinematográficos II, as unidades curriculares cujos alunos integraram este workshop.

Os estudos desenvolvidos por Fleischmann (2015) na área do Design no ensino superior dão nota da crescente preocupação em integrar práticas de colaboração multidisciplinar como parte do currículo dos cursos criados neste âmbito, especialmente os que fazem uso de media digitais e lidam com novas tecnologias, projetos multimedia ou aplicações interativas. Ao mesmo tempo, este tipo de conteúdo de media promove a colaboração entre disciplinas de todos os níveis - "Collaboration, be it in multi-, inter- or transdisciplinary teams means 'to work with another person or group in order to achieve or do something' (Marian-Webster Dictionary)" (FLEISCHMANN, 2015, p. 4-5) -, pelo que se torna pertinente 
testar e avaliar iniciativas curriculares que procurem desenvolver práticas multidisciplinares neste tipo de curso.

Caracterizando estes vários níveis, Choi e Pak (2006) definem multidisciplinar, interdisciplinar e transdisciplinar como conceitos de caráter "respetivamente, aditivo, interativo e holístico". Nesse sentido, diferentes disciplinas podem contribuir com diferentes perspectivas num ambiente multidisciplinar em que a complementaridade é essencial para alcançar um objetivo comum (FLEISCHMANN, 2015, p. 26), uma classificação hierarquizada referida como orientação por Angus e Doherty (2015) no seu estudo sobre ensino de Jornalismo e Design de Interação. Refere Marques (2008) que estratifica os três conceitos pela abrangência da sua intervenção:

multidisciplinarity occurs when a problem in one field is addressed by multiple disciplines. Interdisciplinarity involves not only collaboration between disciplines but also a transfer of concepts, leading to a common conceptual framework. Transdisciplinary collaboration provides a framework that transcends the disciplines (ANGUS; DOHERTY, 2015, p. 2). ${ }^{1}$

$\mathrm{O}$ aspeto importante a atingir no final de uma colaboração em equipe multidisciplinar é consequentemente não a transformação dos perfis individuais iniciais, mas a transformação em comportamentos de relação interdisciplinar e práticas de consequência transdisciplinar consolidadas no produto final dessa colaboração.

Outra componente estruturante nos estudos de Fleischmann e Daniel (2010) e Angus e Doherty (2015) é a necessária relação entre prática curricular de ensino multidisciplinar e o mundo real da prática profissional, nas várias disciplinas envolvidas. Muito concretamente, a utilização de "problemas reais", a participação de agentes profissionais externos e a confrontação dos estudantes com questões de desenvolvimento técnico (ANGUS; DOHERTY, 2015) permitem a construção de cenários reais que replicam os vários passos de acreditação para um produto profissional (FLEISCHMANN; DANIEL, 2010). Este enquadramento é fundamental para se poder desenvolver uma metodologia de educação em design, orientada para a solução de problema focados no mundo real.

A experiência documentada por Brown (2009) é também relevante no contexto das metodologias seguidas para alcançar uma prática multidisciplinar, na educação em design, que seja inclusiva e generativa, dando ao aluno a capacidade de assumir o método como expressão do seu próprio pensamento conceitual. Brown (2009) identifica assim um terceiro caminho, uma abordagem integrada no centro do processo de design, que assenta na habilidade de ser intuitivo, reconhecer padrões, construir ideias que tenham significado emocional, assim como funcional, para nos expressarmos nos media mais do que em palavras e símbolos. Esta emergente demanda dos media requer respostas e abordagens a problemas que estão longe da comum perspectiva do design enquanto introdução de novos produtos físicos. Ela assenta em novas formas de processos, serviços, interações, entretenimento, meios de comunicação e colaboração, todo um leque de atividades centradas no ser humano (BROWN, 2009). A transdisciplinaridade destes processos, iniciativas e soluções, cada vez mais requer a habilidade de construir em colaboração e cooperação equipes de desenvolvimento de projeto, nas esferas prática, acadêmica e científica do design (VIEIRA, 2018). 


\section{CONTEXTO PROFISSIONAL E DESAFIOS DE UMA REDAÇÃO DIGITAL INTEGRADA (JORNALISTAS, DESIGNERS, E PROFISSIONAIS DE IMAGEM)}

A realidade profissional que o workshop escolhe como cenário real, desenvolvendo uma ação de prática curricular em ambiente multidisciplinar, está também em dinâmica evolução e adaptação à realidade profissional do trabalho jornalístico no contexto dos novos media. Os desafios tecnológicos ligados à produção e distribuição de conteúdo jornalístico através de media digitais pedem aos profissionais uma adaptação radical dos seus métodos de trabalho individuais e coletivos, e uma reaprendizagem de competências base nas quais assenta o novo paradigma da edição digital. No conceito de redação digital integrada, associada a um modelo de gestão e inovação crossmedia, duas tendências aparentemente contraditórias têm sido observadas na última década por García-Avilés (2004; 2011): a necessidade de ter jornalistas com múltiplas competências técnicas, "multi-skilling", escrita, imagem e edição digital, e a procura de especializações em novas áreas decorrentes do paradigma digital e relevantes no novo fluxo de trabalho jornalístico, tais como web-designers, programadores, especialistas de dados.

Esta realidade fragmentada representa um desafio para a identificação do perfil disciplinar do jornalista, que assume vários papéis simultâneos mas que incorpora igualmente outros que não faziam parte do corpo essencial de qualificações jornalísticas, ou porque eram laterais ao fluxo de produção, ou porque a sua especialização não era sequer considerada dentro do corpo de saberes da disciplina. Numa realidade simultaneamente multi, inter e transdisciplinar, onde o design assume um papel central como componente da prática jornalística, o desafio num ambiente simulado em contexto curricular de ensino será interpretar essa dinâmica de fluxos e competências e permitir um processo de aprendizagem que facilite a partilha multidisciplinar de conteúdos editoriais e técnicos e a consciência interdisciplinar na construção do produto jornalístico, num fluxo de redação integrada e produção mix-media.

\section{DEFININDO MIX-MEDIA DIGITAL}

A aplicação da designação de mix-media digital (versão abreviada de mixed-media) constrói-se sobre a noção de Ryan (2003), que define uma tipologia de "narrative media", na qual parâmetros como o tipo de signo e o número de canais são usados para resolver a diversidade de possíveis formatos materiais que a narrativa pode assumir. Esta diversidade de carácter material é problematizada e desenvolvida por Jensen (2007), que resgata para o campo da comunicação e dos novos media, integrando a teoria dos autores referência no campo uma perspectiva estética atualizada do termo:

Mixed media' that combine materials in more or less innovative ways are a familiar format in artistic practice and criticism. The aesthetic gaze and the camera eye, as developed by Bolter and Grusin (1999) and by Manovich (2001), are valid perspectives on new, mixed media, as well (Jensen, 2007, p. 21).

Segundo este autor, a nova estética digital tem, pois, que integrar as decorrências das interfaces com os modelos físicos de explicação na sua realidade narrativa. A narrativa mix-media de caráter digital, para cuja redefinição estrutural de Jennings (1996) já tinha contribuído com um conceito de base reconfigurável e polivalente, é posteriormente reforçada por Binder et al. (2004) na sua simulação de ambientes mix-media para alunos de design. 


\section{PROPOSTA EDUCACIONAL E DE APRENDIZAGEM}

A Faculdade de Artes e Letras da Universidade da Beira Interior tem tradicionalmente promovido o ensino de processos de produção digital nos cursos de design multimedia, jornalismo e cinema. A prática curricular de desenvolvimento de projeto não contemplava uma lógica de trabalho multidisciplinar, em equipe. Tendo em conta a pertinência atual do trabalho em equipe multidisciplinar, nomeadamente no contexto editorial do design e do jornalismo digital, em concreto nas redações integradas, e incluindo recentes exemplos desta prática noutros programas universitários de ensino do design (FLEISCHMANN, 2015, p. 4-5), foi desenvolvida uma proposta de trabalho transdisciplinar.

A iniciativa envolveu feedback profissional promovido em parceria com a redação do Expresso.pt. Este jornal, criado em 1973, um ano antes da revolução que resgatou Portugal da ditadura, tornou-se referência para o público através da qualidade e diversidade de conteúdos presentes na sua edição semanal. 0 Expresso foi o primeiro jornal em Portugal a lançar uma versão HTML (online) da sua edição em papel e, mais recentemente, uma edição digital diária - em 5 de maio de 2014. Este último formato serviu de base de prototipagem para o exercício desenvolvido nesta experiência de investigação.

O briefing propôs a realização de um trabalho mix-media jornalístico para publicação no site do jornal Expresso, tendo como tema central para as propostas de artigos “O Estado do País”, em vésperas das eleições legislativas de 2015, nas quais todas as áreas de produção jornalística podiam ser exploradas (entrevista, reportagem, infografia, longo formato, vídeo etc.). A seleção para publicação dos trabalhos finais ficou dependente da edição e aprovação da direção editorial do jornal.

Esta iniciativa procurou atingir seus objetivos integrando disciplinas de cursos existentes com objetivos comuns e elementos de avaliação centrados no desenvolvimento de projeto em grupo multidisciplinar. A avaliação foi efetuada com foco no curso base de cada aluno. Os objetivos de aprendizagem para os alunos foram: conceitualizar e produzir conteúdos jornalísticos para um ambiente digital, social e multiplataforma (multiecrã); aplicar uma validação editorial jornalística aos vários domínios disciplinares envolvidos (Design Multimedia, Jornalismo, Cinema); trabalhar efetivamente como parte de uma equipe multidisciplinar; analisar e avaliar objetos produzidos (peças jornalísticas) dentro do contexto de uma prática que tem como referência uma redação digital integrada. Numa perspectiva de ensino aprendizagem foram examinadas as seguintes questões:

a) Quais os principais desafios associados à integração em equipe de alunos de diferentes programas de ensino e diferentes culturas de aprendizagem?

b) A multidisciplinaridade foi alcançada durante o período em que decorreu a ação do workshop (sete semanas)?

c) Qual foi o impacto na qualidade dos protótipos finais e nos objetivos de aprendizagem da abordagem metodológica, e pedagógica, desta ação?

Os objetivos das unidades curriculares envolvidas, dos três cursos, foram coordenados e a ação realizou-se na mesma sala e ao mesmo tempo. Para encorajar a participação, critérios de avaliação foram incluídos, como presença nas sessões de workshop, ou ausência justificada dos alunos e feedback relativo à contribuição dos outros membros da mesma equipe. Os alunos de jornalismo foram avaliados com base em critérios como valor jornalístico, uso de tecnologia, e composição de conteúdo. Os alunos de design multimedia foram avaliados com base na aplicação de princípios de design da interface, métodos de prototipagem, fluxo da interface (UI) e experiência do utilizador (UX) para conteúdos narrativos e no uso apropriado e inovador de tecnologia. Os alunos de cinema foram 
avaliados com base em critérios como valores de produção de imagem (enquadramento, linguagem de planos, fotografia).

\section{METODOLOGIA E ANÁLISE DO WORKSHOP}

O workshop foi desenvolvido seguindo uma abordagem experimental e semiestruturada que envolveu métodos mistos de investigação, integrando vários procedimentos de análise de dados. Nesta experiência foram combinados dois níveis de ensino, graduação em design multimedia e cinema, e mestrado em jornalismo. Participaram do workshop um total de 68 alunos, 35 de design multimedia com idades compreendidas entre 20 e 28 anos, dezessete de jornalismo com idades entre 20 e 24, com um de 39, e catorze de cinema com idades entre 19 e 24, tendo havido uma desistência. Os alunos constituíram catorze equipes, seis de quatro alunos, e oito de cinco. Na primeira sessão, os estudantes agruparam-se de acordo com o interesse demonstrado nos temas lançados pelos professores e outros propostos pelos próprios colegas (Tabela 1).

Tabela 1: Constituição dos grupos por tema e disciplinas. Fonte:

\begin{tabular}{|c|c|c|c|c|}
\hline Grupo & Tema & Jornalismo & Cinema & $\begin{array}{c}\text { Design } \\
\text { Multimedia }\end{array}$ \\
\hline 1 & Legalização da marijuana & 1 & 1 & 3 \\
\hline 2 & Jovens futebolistas africanos & 1 & 1 & 3 \\
\hline 3 & $\begin{array}{l}\text { Fluxo de alunos brasileiros para } \\
\text { Portugal }\end{array}$ & 2 & 1 & 2 \\
\hline 4 & $\begin{array}{l}\text { Ferramenta web como } \\
\text { autoaprendizagem }\end{array}$ & 1 & 1 & 2 \\
\hline 5 & $\begin{array}{l}\text { Ensino de programação no plano } \\
\text { nacional de educação }\end{array}$ & 1 & 1 & 3 \\
\hline 6 & Acesso de mulheres a cargos & 1 & 0 & 3 \\
\hline 7 & Abandono escolar no ensino superior & 2 & 1 & 2 \\
\hline 8 & Pessoas-marcas & 1 & 1 & 3 \\
\hline 9 & Disruptor digital de media clássicos & 1 & 1 & 2 \\
\hline 10 & $\begin{array}{l}\text { Mudança de mentalidade em relação à } \\
\text { homossexualidade }\end{array}$ & 1 & 1 & 3 \\
\hline 11 & $\begin{array}{l}\text { Falsa criação de emprego através de } \\
\text { investimentos em empresas. }\end{array}$ & 1 & 1 & 2 \\
\hline 12 & Novas profissões on-line & 1 & 1 & 3 \\
\hline 13 & Licenciados em artes, ficar ou partir & 1 & 1 & 2 \\
\hline 14 & Nova economia das artes digitais & 1 & 1 & 3 \\
\hline
\end{tabular}

Os temas foram escrutinados pelo supervisor e professores numa análise de base fatual por detrás das ideias e da sua relevância editorial. O workshop foi desenvolvido ao longo de sete semanas com sessões que decorreram de 13 de abril a 29 de maio de 2015, quatro de trabalho e uma de avaliação (Tabela 2).

Tabela 2: Timeline e atividades das sessões do Workshop. Fonte:

\begin{tabular}{|c|c|c|c|}
\hline $\begin{array}{l}\text { Sessão de } \\
\text { Workshop }\end{array}$ & $10: 00-13: 00$ & $14: 00-16: 00$ & $16: 00-18: 00$ \\
\hline $\begin{array}{l}1 . \\
14 \text { abr. }\end{array}$ & $\begin{array}{l}\text { Lançamento de } \\
\text { proposta de trabalho } \\
\text { do Expresso.pt }\end{array}$ & $\begin{array}{l}\text { Processo de teambuilding } \\
\text { multidisciplinar. } \\
\text { Sessão metodológica } \\
\text { de desenvolvimento de } \\
\text { produto digital. }\end{array}$ & $\begin{array}{l}\text { Trabalho de equipe. } \\
\text { Estúdio } \\
\text { acompanhado. }\end{array}$ \\
\hline
\end{tabular}


Tabela 2: Continuação

\begin{tabular}{|c|c|c|c|}
\hline $\begin{array}{l}\text { Sessão de } \\
\text { Workshop }\end{array}$ & $10: 00-13: 00$ & $14: 00-16: 00$ & $16: 00-18: 00$ \\
\hline $\begin{array}{l}2 . \\
15 \text { abr. }\end{array}$ & $\begin{array}{l}\text { Trabalho laboratorial } \\
\text { de construção de } \\
\text { propostas de projeto } \\
\text { com plano de trabalho } \\
\text { detalhado. }\end{array}$ & $\begin{array}{l}\text { Trabalho laboratorial } \\
\text { de apresentação de } \\
\text { propostas de projeto } \\
\text { com plano de trabalho } \\
\text { detalhado para cada } \\
\text { membro da equipe. }\end{array}$ & $\begin{array}{l}\text { Apresentação das } \\
\text { propostas. }\end{array}$ \\
\hline $\begin{array}{l}3 . \\
29 \text { abr. }\end{array}$ & $\begin{array}{l}\text { Sessão laboratorial de } \\
\text { desenvolvimento dos } \\
\text { projetos. }\end{array}$ & $\begin{array}{l}\text { Trabalho de equipe. } \\
\text { Estúdio acompanhado. }\end{array}$ & $\begin{array}{l}\text { Trabalho de equipe. } \\
\text { Estúdio } \\
\text { acompanhado. }\end{array}$ \\
\hline $\begin{array}{l}4 . \\
20 \text { maio }\end{array}$ & $\begin{array}{l}\text { Sessão laboratorial de } \\
\text { desenvolvimento dos } \\
\text { projetos. }\end{array}$ & $\begin{array}{l}\text { Trabalho de equipe. } \\
\text { Estúdio acompanhado. }\end{array}$ & $\begin{array}{l}\text { Trabalho de equipe. } \\
\text { Estúdio } \\
\text { acompanhado. }\end{array}$ \\
\hline $\begin{array}{l}5 . \\
27 \text { maio }\end{array}$ & $\begin{array}{l}\text { Apresentação final dos } \\
\text { protótipos de projeto } \\
\text { das equipes. }\end{array}$ & $\begin{array}{l}\text { Apresentação e Avaliação } \\
\text { dos Protótipos das } \\
\text { equipes. }\end{array}$ & $\begin{array}{l}\text { Apresentação } \\
\text { e Avaliação dos } \\
\text { Protótipos das } \\
\text { equipes. }\end{array}$ \\
\hline
\end{tabular}

Na segunda sessão começou-se o trabalho conceitual de desenvolvimento dos temas e deu-se início ao sketching de protótipos de baixa resolução (Figura 1). Às duas primeiras sessões seguiram-se duas semanas de intervalo, para acesso a informação, período de incubação e exploração temática de ideias.

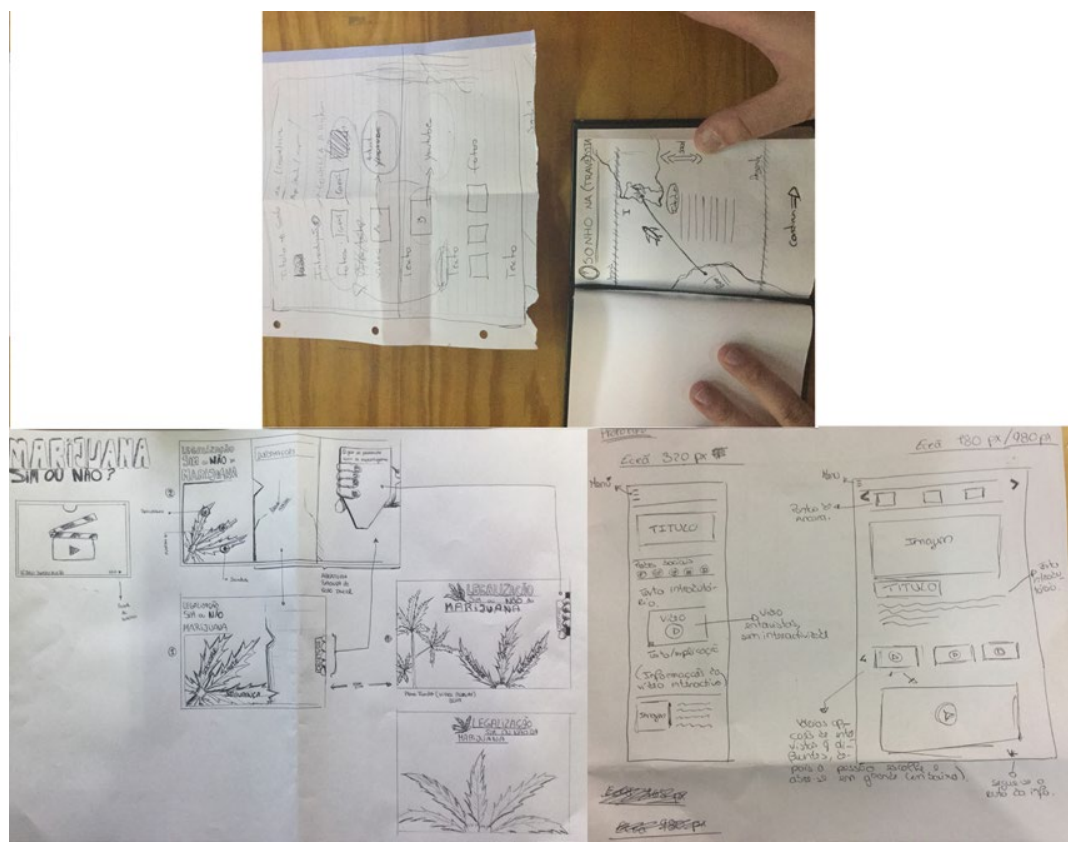

Figura 1: Exemplos de prototipagem em papel. Fonte: Imagem própria.
Na terceira sessão, desenvolveu-se a integração dos conteúdos temáticos produzidos e finalizou-se a fase de conceitualização de protótipos. Houve um intervalo de três semanas, para desenvolvimento das propostas até a quarta sessão, em que se desenvolveu a edição e integração dos conteúdos temáticos num protótipo funcional (Figura 2), de acordo com os guidelines da grelha editorial do jornal Expresso.pt. Por fim, os alunos tiveram uma semana até à sessão final para apresentação de protótipos.

Neste workshop os alunos foram motivados a desenvolver e adequar suas abordagens de trabalho aos fluxos de produção de uma publicação profissional. Nesse sentido, na primeira sessão foi realizada uma reunião de redação alargada para discussão de ideias, na qual foram determinadas 
funções e atividades a realizar como planeamento, recolha e produção de materiais. Nas sessões seguintes foram realizadas outras reuniões de edição dos trabalhos, bem como de finalização funcional dos artigos mix-media. Durante as sessões foi dado feedback regular e validadas as opções das equipes por parte do supervisor externo e dos professores. A supervisão foi feita por um elemento da indústria, que observou, interagiu e deu feedback a partir de uma perspectiva profissional aos alunos. Pedro Monteiro, que trabalha no grupo Impresa, foi convidado a apresentar a proposta de trabalho e estava envolvido nesta experiência. Com formação profissional na área do design é, atualmente, gestor de conteúdos multimedia no jornal Expresso.pt, com participação no planeamento, produção e edição de narrativas digitais, bem como na estratégia de redes sociais do jornal, novos produtos editoriais digitais, entre outros.
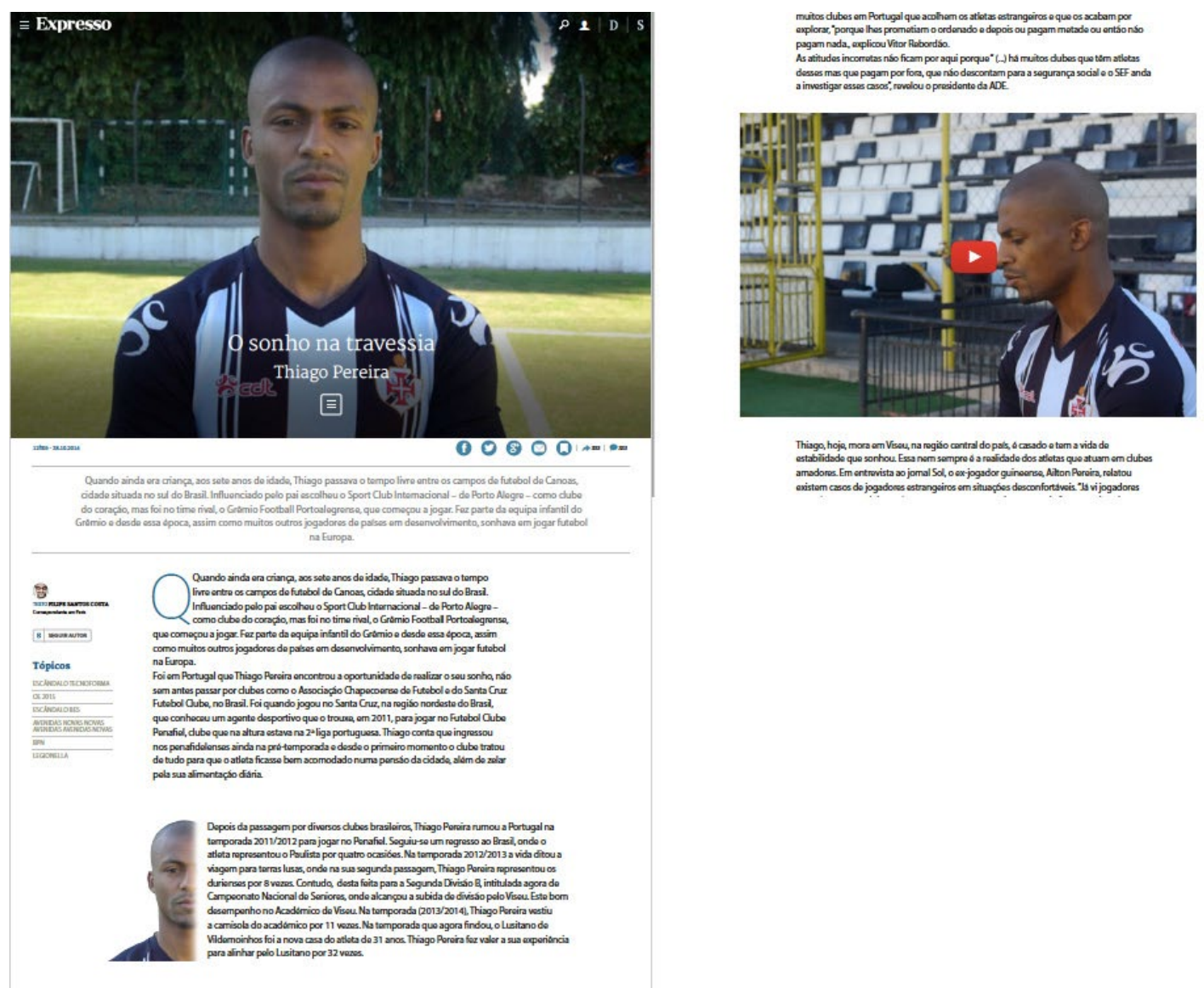

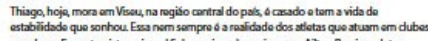

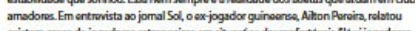

Figura 2: Exemplos de protótipos funcionais. Fonte: Imagem própria. 
TEenotogiss

\section{A Web como método de autoaprendizagem}

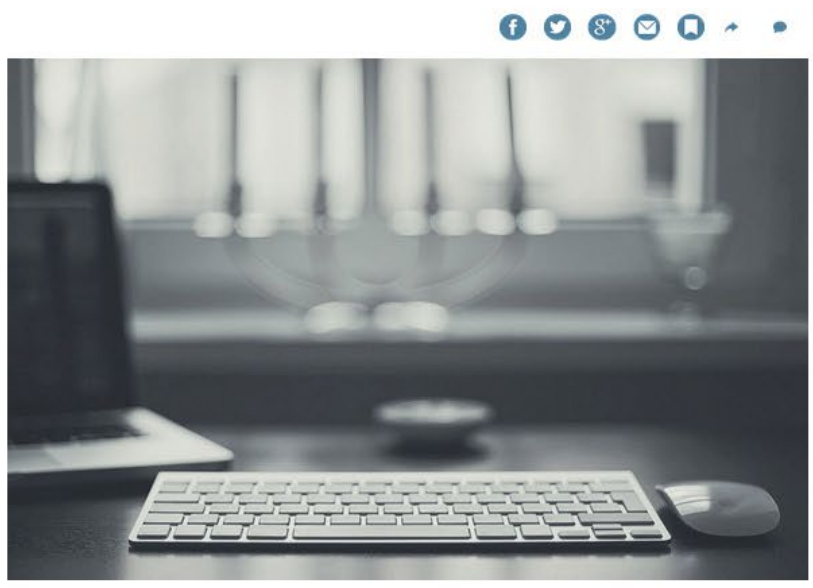

Num mundo cada vez mais dependente da tecnologia, a forma de aprendizagem tem vindo a alterar-se. Nos últimos anos, a autoaprendizagem está cada vez mais presente na vida do ser humano o que permite alargar o seu conhecimento em diversas áreas. 0 excesso de informação na Web e o seu baixo custo tem atraído cada vez mais as pessoas a deslocar-se para a Web, assistindo aos vídeos tutoriais dos conteúdos que pretendem aprender.

Aprender por recriação própria no espaço virtual tem a suas vantagens, mas o cidadão por vezes não encontra a informação prática que pretende saber o que leva a frequentar os cursos de formação.

A autoaprendizagem na área da educação não é um método cem por cento eficaz na aprendizagem de um aluno, mas é uma forma de complementação na sua aprendizagem para obter os bons resultados.

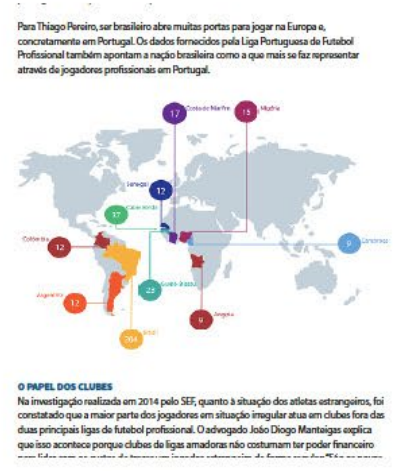

Figura 2: Continuação.

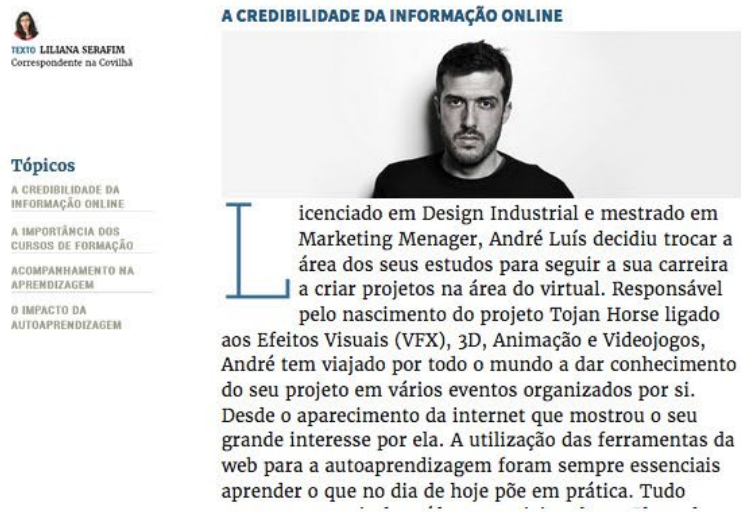

Foi usada uma abordagem de métodos mistos para avaliar esta iniciativa. Os métodos usados foram: inquérito com perguntas de escala ( 0 a 5), um conjunto de cinco perguntas de resposta aberta e duas perguntas de resposta binária; observações dos professores com base qualitativa em notas de diário de workshop, imagem fotográfica, vídeo; protótipos de baixa resolução e protótipos funcionais; comentários e notas do supervisor 
externo. As respostas dos alunos foram recolhidas na última sessão do workshop antes da publicação das classificações.

\section{ANÁLISE QUALITATIVA E QUANTITATIVA}

\section{Análise das Respostas dos Alunos}

Dos 68 alunos envolvidos, $54(79,4 \%)$ responderam ao inquérito e perguntas, dos quais $46,3 \%$ são mulheres $(\mathrm{N}=25)$. Os valores médios (M) indicados na análise são relativos a uma escala de 0 a 5. Das 54 respostas, $44,4 \%$ correspondem a alunos de licenciatura em Cinema $(\mathrm{N}=8)$ e mestrado em Jornalismo $(\mathrm{N}=16)$, e $55,6 \%$ correspondem às respostas de alunos de licenciatura em Design Multimedia $(\mathrm{N}=30)$.

Dos resultados gerais, obtivemos uma receptividade moderada dos alunos à iniciativa $(\mathrm{M}=3,22)$ influenciada pela avaliação do workshop abaixo da média de três destes. Tendo em conta o desequilíbrio provocado pela avaliação destes alunos, os participantes foram agrupados em cinco categorias de acordo com a receptividade à iniciativa e o sucesso do desempenho ao longo do workshop, de forma a melhor interpretar os resultados e desenvolver análises concorrentes dos dados, aferindo assim diversos aspetos. Depoimentos dos alunos acompanham a análise dos cinco grupos em análise.

Grupo dos desconectados (N=3). Estes alunos não atribuíram um valor positivo à iniciativa $(\mathrm{M}=2)$ e demonstraram alguma falta de sentimento de competência por não se sentirem preparados para o workshop $(\mathrm{M}=1,75)$. Estes estudantes revelam problemas no relacionamento e colaboração com colegas do mesmo curso de outras equipes de trabalho $(\mathrm{M}=2,75)$, sendo abaixo da média com colegas de curso diferente $(M=2,25)$, e com colegas de outros cursos em equipes diferentes $(M=1)$. Contudo, revelaram-se moderadamente motivados em relação ao tema proposto $(M=2,75)$, aos recursos disponibilizados $(\mathrm{M}=3)$, com o trabalho de campo $(\mathrm{M}=4)$, menos motivados, embora acima da autoavaliação, acerca da competência dos colegas $(M=2,5)$ e sua disponibilidade $(M=2,25)$, mas satisfeitos com a concretização do projeto $(M=3)$. Estes alunos referem que mais comunicação com colegas de outras equipes, mais tempo para a concretização do projeto, e foco temático de igual interesse para os diferentes membros das equipes multidisciplinares, evitariam a desmotivação dos outros elementos dos grupos (jornalismo em detrimento do design e cinema).

Trabalhar com um grupo é sempre diferente, e trabalhar com um grupo de pessoas de outras áreas ainda mais. Em cinema, nós já ganhamos bases para criarmos narrativas através da mais mínima coisa, e este trabalho não foi exceção (Participante não identificado).

Grupo dos sobreviventes desmotivados $(\mathrm{N}=15)$. Estes alunos mostraram-se moderadamente recetivos à iniciativa do workshop $(\mathrm{M}=3)$, e medianamente preparados $(\mathrm{M}=2,5)$. Os alunos revelam relacionamento e colaboração média com colegas do mesmo curso de outras equipes de trabalho $(M=2,53)$, sendo melhor com colegas de curso diferente na sua equipe $(M=2,93)$, e abaixo da média com colegas de outros cursos em equipes diferentes $(M=1,53)$. Estes alunos mostram receptividade ao trabalho multidisciplinar. Revelam motivação mediana em relação ao tema proposto $(M=2,6)$, aos recursos disponibilizados $(M=2,8)$, e moderada com o trabalho de campo $(\mathrm{M}=3)$, mas abaixo da média em relação à competência dos colegas $(M=2,26)$, sua disponibilidade $(M=2,13)$, e concretização tangente do projeto $(M=2,53)$. Estes alunos referem que um pouco mais de formação ajudaria a que alunos das diversas áreas 
ficassem a conhecer melhor o tipo de técnica a utilizar no trabalho final. Não se sentiram suficientemente preparados para a dimensão do trabalho, porém, consideram uma experiência reveladora da realidade no mundo do trabalho. Estes alunos tiveram dificuldades na organização inicial do trabalho. Sugerem mais tempo para o workshop, a começar no início do semestre. Outros sentem-se preparados com a aprendizagem anterior dos cursos base. Alguns reclamam de falta de recursos, e outros de que as equipes deveriam ter mais alunos.

Iniciá-lo com mais tempo, e não a meio do semestre. A organização dos grupos e os valores da avaliação também deveriam de ser iguais para todos, porque o valer mais para uns e menos para outros pode levar a que alguns elementos não se interessem pelo projeto. Fazer avaliações a todos os grupos durante o workshop também ajudaria talvez a que os elementos se interessassem mais (Participante não identificado).

Grupo dos sobreviventes motivados $(\mathrm{N}=15)$. Estes alunos mostraramse receptivos à iniciativa do workshop $(\mathrm{M}=3)$, e medianamente preparados $(\mathrm{M}=2,6)$. Os alunos revelam relacionamento e colaboração média com colegas do mesmo curso de outras equipes de trabalho $(\mathrm{M}=2,4)$ e com colegas de curso diferente na sua equipe $(\mathrm{M}=2,46)$, e abaixo da média com colegas de outros cursos em equipes diferentes $(M=1,66)$. Estes alunos revelam relação semelhante com colegas na área interdisciplinar e multidisciplinar. Revelam-se bem motivados com o tema proposto $(M=3,66)$, recursos disponibilizados $(M=3,33)$, e com o trabalho de campo $(M=3,4)$, assim como com a competência dos colegas $(M=3,86)$, sua disponibilidade $(M=3,73)$, e concretização do projeto $(M=3,66)$. Estes alunos referem que mais tempo para o workshop e mais pessoas por grupo como aspetos a considerar. Apreciaram a experiência de trabalho multidisciplinar e o feedback dos professores e observador/supervisor externo da indústria. Sugerem que uma comunicação antecipada do esquema do projeto final teria acelerado a eficácia do processo. De modo geral sentem-se preparados com a aprendizagem anterior para o desafio.

As aulas que antecederam a realização do projeto serviram para ter noções sobre o que tinha de ser feito. No que toca à produção do texto, a experiência que tivemos ao longo da licenciatura e do mestrado ajudam-nos a estar familiarizados (Participante não identificado).

Grupo dos curiosos $(\mathrm{N}=6)$. Estes alunos mostraram-se receptivos à iniciativa do workshop $(\mathrm{M}=3,33)$, e razoavelmente preparados e expectantes $(\mathrm{M}=3)$. Os alunos revelam relacionamento e colaboração média com colegas do mesmo curso de outras equipes de trabalho $(M=2,50)$ sendo melhor com colegas de curso diferente na sua equipe $(\mathrm{M}=3,16)$, e abaixo da média com colegas de outros cursos em equipes diferentes $(M=2,33)$. Estes alunos são os que mostram maior receptividade ao trabalho multidisciplinar. Revelam motivação moderada em relação ao tema proposto $(\mathrm{M}=3,16)$, aos recursos disponibilizados $(M=3,50)$, e com o trabalho de campo $(M=3,33)$, assim como em relação à competência dos colegas $(\mathrm{M}=3)$, e um pouco melhor quanto à sua disponibilidade $(\mathrm{M}=3,33)$, e concretização do projeto $(\mathrm{M}=3,66)$. Estes alunos referem que deveria ser dado mais tempo ao workshop, a começar no início do semestre. Alguns alunos referem que uma orientação de edição editorial e estrutura narrativa mais forte do que a que foi dada, poderia ter sido útil. Pode também revelar alguma falta de autonomia na produção de conteúdo jornalístico. Contudo sentem-se preparados com a aprendizagem em várias unidades curriculares, considerando que construir este tipo de narrativa é uma das bases do percurso acadêmico. 
No âmbito do mestrado, já pesquiso narrativas transmedia, foi fácil adaptar os conteúdos para tal, tendo o suporte multimedia para construção (Participante não identificado).

Grupo dos motivados e confiantes $(\mathrm{N}=16)$. Estes alunos mostraramse bastante receptivos à iniciativa do workshop $(\mathrm{M}=4)$, e razoavelmente preparados $(\mathrm{M}=3,20)$. Revelam bom relacionamento e colaboração com colegas do mesmo curso de outras equipes de trabalho $(\mathrm{M}=3,44)$ sendo moderado com colegas de curso diferente na sua equipe (M=2,87), e abaixo da média com colegas de outros cursos em equipes diferentes $(M=1,62)$. Revelaram-se motivados em relação ao tema proposto $(\mathrm{M}=3)$, aos recursos disponibilizados $(M=3,25)$, e com o trabalho de campo $(M=3,25)$, abaixo da média com a competência dos colegas $(M=2,37)$, e um pouco melhor quanto à sua disponibilidade $(M=2,68)$, e concretização do projeto $(M=2,81)$. Estes alunos referem que mais tempo para o workshop, a começar no início do semestre, com palestras e seminários ao longo do mesmo seriam benéficos para uma melhor flexibilidade de trabalho e ideias. Os alunos referem problemas na cooperação de colegas, que por inação, prejudicaram o trabalho final dependente das suas contribuições. Ressalvam que para o tempo proposto, a meio do semestre e com outras entregas de trabalho simultâneas, temáticas menos utópicas e mais viáveis seriam mais apropriadas ao contexto.

Após uma longa aprendizagem em várias unidades curriculares, considero que construir este tipo de narrativa é uma das bases do nosso percurso acadêmico (Participante não identificado).

No geral, alguns alunos referiram que gostariam que as atividades conjuntas possam ir um pouco mais longe e ter mais oportunidades de interagir com os seus parceiros profissionais. Algumas aulas teóricas conjuntas poderiam ter ajudado a melhor compreender as culturas de aprendizagem dos diferentes cursos. Houve alguma incerteza quanto ao papel dos alunos de cinema nas equipes. Numa próxima experiência, sugerem estruturar o workshop para que o papel dos jornalistas seja mais ativo, e não apenas de incorporação do valor jornalístico, e se possível determinar com maior clareza as tarefas a realizar pelos alunos das diferentes disciplinas, para que estas não sejam vagas e difíceis de encetar.

\section{Notas da Observação dos Professores}

Foram detetados problemas de trabalho conjunto nalgumas equipes que tiveram dificuldade em se organizar, distribuir tarefas e encetar trabalho de redação. Poucos grupos fizeram análise de usabilidade e testes. Alguns grupos tiveram dificuldades de acesso à informação de fontes seguras, centros de investigação e de encontrar pessoas com disponibilidade e receptividade a falar e partilhar as suas histórias.

Foi verificado que os alunos de jornalismo também pensam em usabilidade, para saber se o que estão a idealizar resulta. Apesar do desenho dos storyboards, na qual é representada a história/narrativa da interação, ajudar a estruturar os conteúdos, o feedback dos jornalistas à interação também se revelou essencial.

No desenvolvimento das soluções foram identificados dois erros clássicos: esquecer de fechar a narrativa, o que resulta numa ideia vaga acerca da mesma, e dispensar muito tempo com a interface.

Das notas de observação são enfatizados os seguintes aspetos a melhorar: desenvolver pensamento programático; fechar a narrativa; eficaz distribuição do trabalho na equipe; distribuição atempada das atividades específicas do design como desenho da interface; acesso à informação e 
pesquisa assegurado; assegurar a apresentação de protótipo funcional e responsivo; assegurar leitura de incidência, visibilidade, proporção, e leitura de comprimento e áreas, melhorar a experiência da leitura; equilíbrio de importância relativa dada aos elementos de composição de redação e design; estruturar e selecionar os elementos essências da informação na narrativa; não forçar uma história para caber na imagem nem precipitar conclusões; agendar testes de usabilidade, imagem, vídeo e som; alertar para a importância do ângulo adotado na entrevista (perspectiva, cenário, visibilidade); comunicar truques de representação de áudio e foto galeria; assegurar a comparência e participação de alunos; e, por fim, a necessidade de desenvolver uma linguagem partilhada pelos alunos de cada grupo, e de entender a linguagem de cada um, de acordo com a sua disciplina base.

Algumas tarefas foram comuns a jornalistas, designers e cineastas, tais como edição de vídeo, filmar entrevistas, definir títulos e colocação de destaques, estabelecer contatos, identificar quem entrevistar (profissionais, pacientes, vítimas, sujeitos em causa), criação de mapeamentos, identificação de impactos, análises nacionais e internacionais, pesquisa de estatísticas, motivos e sua representação, estudos e foto galerias.

Os alunos de cinema focaram-se em questões de estética do ambiente da entrevista e na qualidade de vídeo, imagem, som e edição. Os alunos de jornalismo focaram-se nos conteúdos e na estruturação das questões das entrevistas, e-mails, layout e estrutura da redação da narrativa. Os alunos de design focaram-se na estrutura da narrativa mix-media, com base nas linhas orientadoras de cada grupo, assegurar leitura de conteúdos, soluções de comunicação, paginação e estética, de infografia interativa, visualização em vários dispositivos, e pesquisa de imagens, grafites e campanhas publicitárias.

No geral, os alunos envolveram-se em atividades tendo em vista questões centrais como: procurar algo diferente; encontrar fundamento e propósito na aplicação dos temas; encontrar sentido no início dos temas e no trabalho de equipe; análises de contraste entre gerações; ser crítico em relação à não aceitação de factos; manifestações públicas de tabus; ter feedback; foco na mudança, o antes e o depois, análise de alteração de hábitos; identificação de tendências; identificação de indicadores de reação para lá das entrevistas; análise de estratégias para obtenção de informação e ética profissional; estar atento a fontes de informação alternativas e novos serviços; potencialidades econômicas; e análise de sucesso e insucesso. Estas notas integraram análise de conteúdos de fotografia e vídeo registados em diário durante as sessões de trabalho.

\section{Notas do Observador Externo da Indústria} refere:

Dos principais desafios associados à experiência o observador externo

colocar em conjunto, em formato de equipe, alunos de diferentes programas de ensino e diferentes culturas de aprendizagem, e convencê-los de que os grupos não seriam feitos com os seus amigos, mas com completos estranhos, alunos de outros cursos. Esta condição permitiu um reflexo do mundo real onde raramente escolhemos com quem vamos trabalhar. Depois, as diferentes valências dos alunos criavam à partida algum tipo de dificuldades: esperava-se que os alunos de design (por exemplo) fossem menos participativos em ideias para histórias do que os alunos de jornalismo. O formato de workshop criado tentou dar resposta a este tipo de problemas e com algumas exceções, foi capaz de o fazer. Finalmente, as diferenças de grau de ensino dos alunos (alunos de mestrado com alunos de $2^{\circ}$ ano) também foi uma dificuldade, uma vez que a experiência de cada um na realização de trabalhos 
era diferente. A multidisciplinaridade foi alcançada durante o período em que decorreu a ação do workshop. Alguns trabalhos foram majoritariamente realizados por alunos de um curso com muito pouca participação de outros, mas no final e olhando para os melhores projetos, aqueles que melhor trabalharam em conjunto conseguiram as melhores soluções (Pedro Monteiro, Expresso.pt).

\section{Quanto aos protótipos finais, o observador externo notou que:}

tendo em conta que o desafio não era nada fácil (mesmo nas redações existe uma grande dificuldade de desenvolver o tipo de objeto jornalístico que pedimos neste workshop) e, olhando para os resultados isso é óbvio. Em termos do formato do workshop, e na livre escolha de temas, talvez tenha jogado contra nós. Imagino que a imposição de temas mais adaptados à realidade dos alunos (por exemplo, a dificuldade em sair da Covilhã para ir fazer reportagem a outros pontos do país), embora pudesse parecer menos interessante à partida, poderia ter jogado melhor a favor dos resultados finais. Finalmente, algumas das ideias propostas acabaram por ser ambiciosas demais, em termos reais de produção jornalística e isso prejudicou os alunos (Pedro Monteiro, Expresso.pt).

Quanto aos objetivos de aprendizagem do workshop o observador externo refere:

O workshop funcionou relativamente bem. A multidisciplinaridade é uma exigência na produção de conteúdos multimedia e não funciona quando feita em silos. Nesse sentido, é ideal que uma equipe tenha a percepção de como é feita cada parte de todo o processo. Pondo os alunos das várias áreas a colaborar em todas as fases do processo, conseguimos que estes ficassem com uma ideia muito aproximada da realidade deste tipo de construção de conteúdos. Na gestão de tempos, produção e finalização do trabalho, notamos a 'normal' faceta jovial de deixar tudo para última, o que denota alguma falta de conhecimento em relação à produção deste tipo de conteúdos. Acho que neste campo não foi por falta de aviso dos professores. Com mais experiência neste tipo de exercícios por parte dos alunos, o planeamento e gestão de tempo correria melhor (Pedro Monteiro, Expresso.pt).

$\mathrm{Na}$ sua avaliação do workshop e iniciativa transdisciplinar, Pedro Monteiro fez outras observações pontuais relevantes, tais como: alguns projetos poderiam ser aplicados no jornal com algum trabalho extra; outros projetos que, pela natureza rebelde, surpreenderam pela inovação, não respeitando as linhas orientadoras do expresso; os projetos não incorporaram suficientemente interatividade; deveria notar-se mais aplicação de conhecimentos teóricos e fundamentos da gestão de informação; necessidade de melhor argumentar na defesa das decisões acerca das narrativas e histórias apresentadas assim como na escolha de fontes de notícias e informação; da influência que os valores próprios dos alunos e juízos de valor têm sobre a forma dada ao projeto assim como esses mesmos valores individuais e sociais sobressaltam nas notícias e narrativas de projeto; da nivelação das notícias, quando uma hierarquia pode melhorar a comunicação da narrativa; problemas de acesso à informação e reconhecimento.

\section{DISCUSSÃO E IMPLICAÇÕES PARA PESQUISA FUTURA}

Esta experiência educativa teve por objetivo desenvolver uma abordagem transdisciplinar num processo de integração que permitiu identificar 
dificuldades e aspetos a melhorar em futuras experiências semelhantes. Dos resultados das respostas dos alunos, e a partir das notas dos professores e observador externo podemos inferir as seguintes implicações relativamente às perguntas de investigação colocadas:

a) motivar a colaboração e cooperação entre alunos que se desconhecem, coordenação das valências de cada aluno por equipe.

b) No final do workshop, os alunos não só ficaram com uma ideia concreta sobre a forma de trabalho conjunto de equipes multidisciplinares dentro de uma redação, como exploraram as aptidões criativas, ladeadas pelas normais limitações de trabalho e publicação em plataformas digitais, necessárias à produção de conteúdos jornalísticos atuais e seus diferentes suportes digitais.

c) Os projetos protótipos dos alunos demonstraram um vasto leque de soluções de design para narrativas mix-media. Os catorze protótipos apresentados mostraram uma combinação de conteúdo de media sociais publicado juntamente com jornalismo profissional. Das aprendizagens para os alunos de design destacam-se: o desenvolvimento das capacidades de conceitualizar e produzir artigos mix-media para um ambiente digital, interativo e social de media móveis; aplicar pensamento e avaliação de design em meios alternativos; trabalhar eficazmente como parte de uma equipe multidisciplinar; analisar e avaliar as soluções propostas no contexto da prática jornalística e do cinema.

Sugestões relevantes para pesquisa futura e melhorias na abordagem metodológica e pedagógica da experiência de ensino são indicadas: integrar alunos do mesmo nível de ensino; sessões de esclarecimento sobre organização de trabalho em equipe multidisciplinar; distribuição de tarefas e maior trabalho de redação; garantir e viabilizar para cada tema de trabalho de equipe acesso a informação pertinente; alertar para distribuição equilibrada nos tempos de execução de tarefas (linhas orientadoras indicadas nas notas da observação dos professores). A aplicação de conhecimentos teóricos fundamentados assim como a capacidade de argumentação nas decisões, o desenvolvimento de uma linguagem partilhada pelos alunos de cada grupo e a motivação para o entendimento da linguagem de cada um, de acordo com a sua disciplina base, são necessidades que em conjunto revelam falta de preparação e experiência curricular prática de colaboração multidisciplinar.

Os resultados obtidos permitem corroborar o déficit inicial percebido nos hábitos de trabalho multidisciplinar em ambiente curricular e a necessidade de aumentar a integração de cenários do "mundo real" na resolução de problemas ao nível da prática acadêmica no ensino do design.

\section{AGRADECIMENTOS}

À participação dos alunos do mestrado de Jornalismo, unidade curricular de Produção Jornalística, e dos alunos da licenciatura de Cinema, unidade curricular de Gêneros Cinematográficos II, foi fundamental para a realização do estudo, bem como a colaboração e o envolvimento ativo durante as sessões dos Professores José Ricardo Carvalheiro e Manuela Penafria, pelo que deixamos aqui um agradecimento especial a todos. De igual modo o enquadramento e a supervisão profissional de Pedro Monteiro, em representação do Expresso.pt, foi estruturalmente importante na proposta de trabalho apresentada, na condução das sessões e na sua avaliação. As suas notas de observação durante as sessões e comentários finais, tendo em conta os “objetivos de aprendizagem”, fazem parte integrante deste trabalho. 


\section{REFERÊNCIAS}

ANGUS, D.; DOHERTY, S. Journalism meets interaction design: an interdisciplinary undergraduate teaching initiative. Journalism \& Mass Communication Educator, Thousand Oaks, v. 70, n. 1, p. 44-57, 2015

AUSTIN, S. et al. Mapping the conceptual design activity of interdisciplinary teams. Design Studies, Amsterdam, v. 22, n. 3, p. 211-232, 2001.

BINDER, T. et al. Supporting configurability in a mixed-media environment for design students. Personal and Ubiquitous Computing, New York, v. 8, n. 5, p. 310-325, 2004.

BROWN, T. Change by design: how design thinking transforms organizations and inspires innovation. New York: Harper Collins, 2009.

CHOI, B. C.; PAK, A. W. Multidisciplinarity, interdisciplinarity and transdisciplinarity in health research, services, education and policy: 1. Definitions, objectives, and evidence of effectiveness. Clinical and Investigative Medicine, Oxford, v. 29, n. 6, p. 351-364, 2006.

FLEISCHMANN, K. Overcoming disciplinary boundaries in undergraduate design education: preparing digital media design students for collaborative multidisciplinary research practice. In: AUSTRALIAN COUNCIL OF UNIVERSITY ART AND DESIGN SCHOOLS CONFERENCE, 6., Adelaide. Proceedings... Camberra: ACUADS, 2008. Disponível em: <https:// goo.gl/xUNk67>. Acesso em: 9 mar. 2016.

FLEISCHMANN, K. A successive approach to multidisciplinary teamwork in undergraduate design education: from dysfunctional to functional teams. Arts and Design Studies, [s.l.], v. 37, p. 25-35, 2015. Disponivel em: <https://goo.gl/7R9y4f>. Acesso em: 7 abr. 2016.

FLEISCHMANN, K., \& DANIEL, R. J. Increasing authenticity through multidisciplinary collaboration in real-life scenarios in digital media design education. CoDesign, Abingdon, v. 6, n. 2, p. 61-74, 2010. Disponível em: <https://goo.gl/ KjxBav>. Acesso em: 7 abr. 2016.

GARCÍA-AVILÉS, J. A. Innovation management in crossmedia production: Leading change in the newsroom. In: IBRUS, I.; SCOLARI, C. A. (Eds.). Crossmedia innovations: texts, markets, institutions. Bern: Peter Lang, 2012. p. 259-276.
GARCÍA-AVILÉS, J. A.; CARVAJAL, M. Integrated and cross-media newsroom convergence: two models of multimedia news production: the cases of novotécnica and la verdad multimedia in Spain. Convergence, Thousand Oaks, v. 14, n. 2, p. 221-239, 2008

GARCÍA-AVILÉS, J. A. et al. Journalists at digital television newsrooms in Britain and Spain: workflow and multi-skilling in a competitive environment. Journalism Studies, Abingdon, v. 5, n. 1, p. 87-100, 2004.

HUANG, E. et al. Facing the challenges of convergence: media professionals' concerns of working across media platforms. Convergence, Thousand Oaks, v. 12, n. 1, p. 83-98, 2006

JENKINS, $\mathrm{H}$. The cultural logic of media convergence. International Journal of Cultural Studies, Thousand Oaks, v. 7, n. 1, p. 33-43, 2004

JENNINGS, P. Narrative structures for new media: towards a new definition. Leonardo, Cambridge, MA, v. 29, n. 5, p. 345-350, 1996.

JENSEN, K. B. Mixed media: from digital aesthetics towards general communication theory. Northern Lights, [s.l.], v. 5, n. 1, p. 7-24, 2007

MARQUES, J. M. M. C. Inter and multidisciplinarity in engineering education. International Journal of Mechanics and Materials in Design, Cham, v. 4, n. 2, p. 229237, 2008.

MEADOWS, D. Digital storytelling: researchbased practice in new media. Visual Communication, Thousand Oaks, v. 2, n. 2, p. 189-193, 2003.

RYAN, M.-L. On defining narrative media. Image \& Narrative, Leuven, n. 6, medium theory, p. 1-7, 2003. Disponível em: <https:// goo.gl/GYaeLT>. Acesso em: 9 mar. 2016.

SZENASY, S. School survey 2004: do America's design schools encourage interdisciplinary collaboration? Metropolis, New York, p. 88-91, 1 Aug. 2004.

VIEIRA, S. Transdisciplinary design: the environment for bridging research across and beyond design as a discipline. In: BLESSING, L.; QURESHI, A. J.; GERICKE, $K$. (Eds.). The future of transdisciplinary design: proceedings of the workshop on "the future of transdisciplinary design". London: Springer-Verlag, 2018. No prelo. sonia.vieira@inegi.up.pt

Luís Manuel Frias

Imfm@ubi.pt 